\title{
EL ENTIERRO DEL SITIO CERRO SOTA (MAGALLANES, CHILE) A MÁS DE SETENTA AÑOS DE SU EXCAVACIÓN
}

\author{
G. LORENA L'HEUREUX" Y TOMAS AMOROSI"
}

\begin{abstract}
RESUMEN
En este trabajo se presentan los resultados del análisis detallado de los materiales óseos que componen el entierro múltiple de la Cueva Cerro Sota (Campo Vocánico Pali Aike; Chile), excavado por el arqueólogo americano Junius Bird en 1936. Se analizan las modificaciones tafonómicas pre y posdepositacionales y los procesos fisiológicos y patológicos que afectaron los nueve individuos identificados en el sitio (seis que componen el entierro y tres hallados por fuera de la estructura), actualmente depositados en la División de Antropología del Museo Americano de Historia Natural de Nueva York. Del análisis de las variables antrópicas se desprende que las evidencias de alteración térmica intencional en los esqueletos no alcanzarían para definir a este entierro como cremación, considerando más adecuado interpretar los rastros de la acción del fuego como combustión parcial del entierro. El panorama que involucra la muerte de siete individos (seis procedentes del entierro aquí analizados y uno extraviado) a comienzos del Holoceno tardío en Pali Aike meridional (ca. 3.600 años AP.), se relacionaría con el incremento de la mortalidad derivada de la mayor densidad poblacional del área inferida para momentos posteriores al 4.000 AP., aunque las causas precisas de los decesos simultáneos siguen sin conocerse.
\end{abstract}

PALABRAS CLAVES: entierro múltiple, comienzos Holoceno tardío, combustión parcial.

\section{THE BURIAL OF CERRO SOTA SITE (MAGALLANES, CHILE) OVER SEVENTY YEARS AFTER ITS EXCAVATION}

\section{ABSTRACT}

This work presents the results of the detailed analysis of the bone material that make up the multiple burial in Cerro Sota Cave (Pali Aike Volcano Field, Chile), excavated by the American archaeologist Junius Bird in 1936. Pre and postdepositional taphonomic changes are analysed together with the pathologic and physiological processes that affected the nine individuals identified at the site (six were part of the burial while three were found outside the structure). This material are currently housed at the Anthropo-

IMHICIHU (CONICET). Saavedra 15, 5ำ piso (1083 ACA). Buenos Aires, Argentina. E-mail: lorenalheureux@yahoo.com.ar

* Division of Anthropology, American Museum of Natural History. Central Park West, 79th Street, New York. EE.UU. E-mail: tamorosi@ix.netcom.com 
logy Division of the American Museum of Natural History of New York. An analysis of anthropic variables shows that the evidence of intentional thermal alteration of the skeletons are not enough to define this burial as cremation, and that the traces of fire action are more appropriately interpreted as partial combustion of the burial. The scenario that involves the death of seven individuals (six from the burial site here analyzed and one that is lost) at the beginning of the late Holocene in southern Pali Aike (ca. 3.600 años BP.) could be related with increased mortality due to the greater population density inferred for the area after $4.000 \mathrm{BP}$., although the precise causes of the simultaneous deaths are still unknown.

KEYWORDS: multiple burial; late Holocene beginning; partial combustion.

\section{EL SITIO CERRO SOTA}

Cerro Sota es una cueva cercana al río Chico localizada en el sector meridional de la Region Volcánica de Pali Aike (CVPA), república de Chile $\left(52^{\circ}\right.$ 04' 0,00" S; 70 03' 0.00" W; Fig. 1). La cueva de origen volcánico está emplazada en la unidad volcánica 2 del campo de lava (Fig. 1) la cual ocupa el 15\% del CVPA. La formación de esta unidad tiene una antigüedad comprendida entre 2,1 millones de años y 300.000 años AP. (D’Orazio et al. 2000).
La cueva se localiza a unos 30,48 mts de altura en un lugar destacado de la ladera este del cerro Sota. Presenta una morfología particular, la cual debió limitar su uso como sitio de habitación en el pasado ya que tiene una entrada muy pequeña que impide el ingreso de luz (Bird 1988: 202) y es muy angosta (1,52 mts de ancho y 14,63 mts de longitud desde la línea de goteo al momento de la excavación; Bird 1988: 202), aunque cuenta con un sector más amplio en el fondo denominado por Bird como cámara interior (Fig. 2).

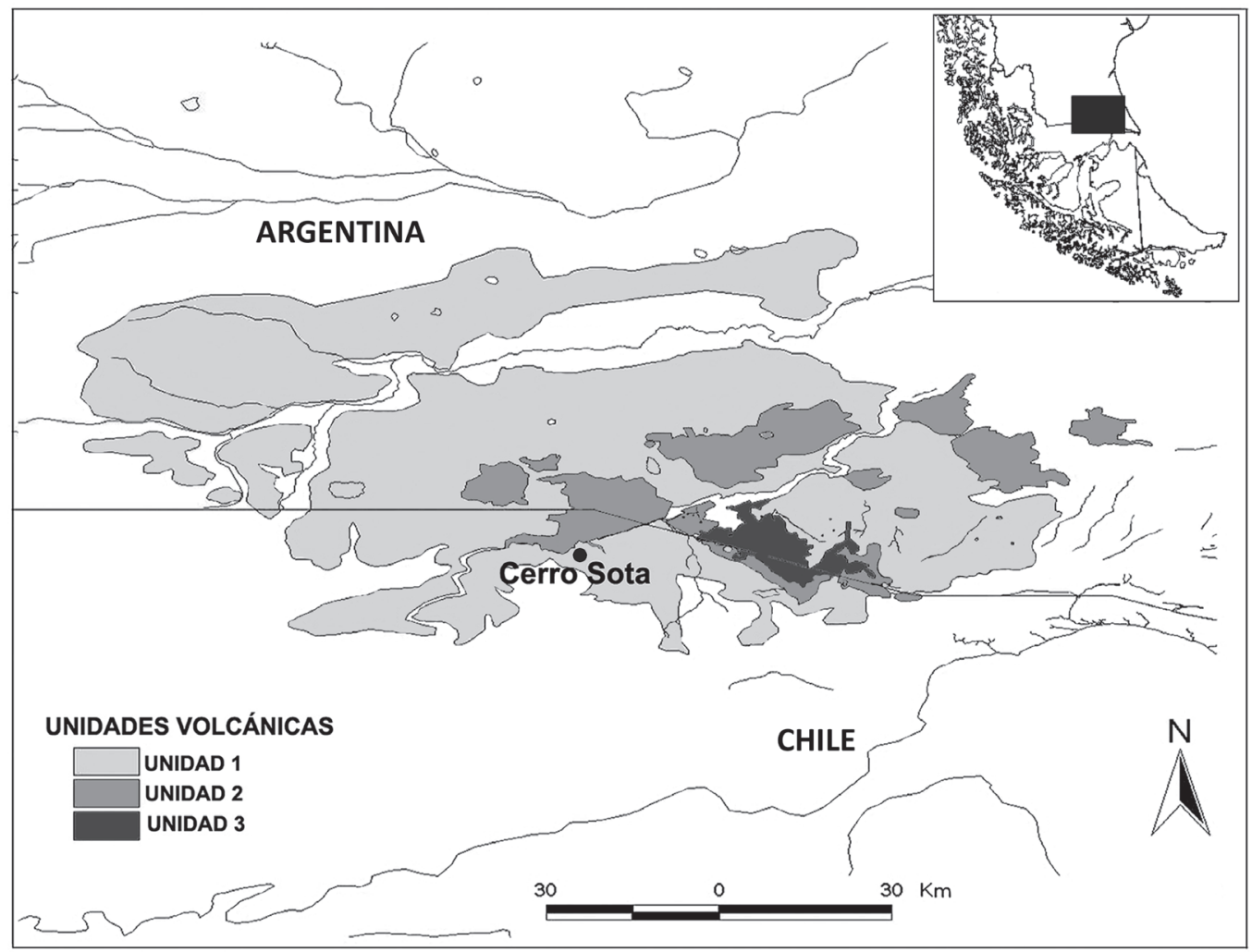

Fig. 1. Localización del sitio Cerro Sota en el campo volcánico Pali Aike (CVPA). 


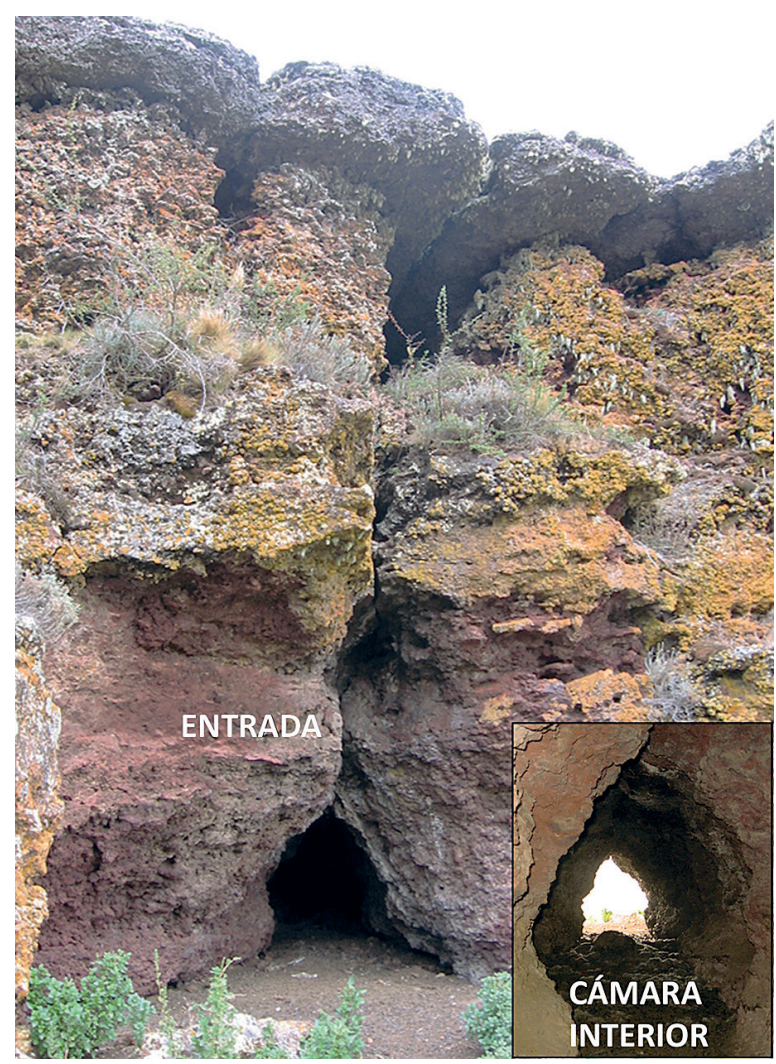

Fig. 2. La Cueva Cerro Sota. Vista de la entrada y de la cámara interior. Imágenes cedidas por R. Barberena.

Este sitio fue excavado a partir de niveles arbitrarios por Junius Bird en diciembre de 1936. En la cámara interior se hallaron pocos artefactos líticos y restos de fauna, principalmente moderna (Lama guanicoe), extinguida (Hippidion saldiasi y Mylodon sp.) y un enterratorio sincrónico múltiple de siete individuos (Bird 1988: 210).

La figura 3 expone el diagrama de la disposición de los individuos en el entierro múltiple hallado por debajo de los $99 \mathrm{~cm}$ de profundidad (Bird 1988: Fig. 90). Los cuerpos fueron depositados en un cavidad excavada intencionalmente para tal fin de 1,22/1,37 mts de diámetro y 60,96 cm de profundidad (Bird 1988: 210). Debajo y entre los individuos se colocaron gramíneas y por sobre los cuerpos grandes bloques de roca volcánica. Como parte del rito de inhumación los pastos fueron incendiados quemando parcialmente algunos de los individuos antes de cubrirlos con el sedimento removido (Bird 1988: 211). En esta estructura de entierro los esqueletos se encontraban dispuestos de

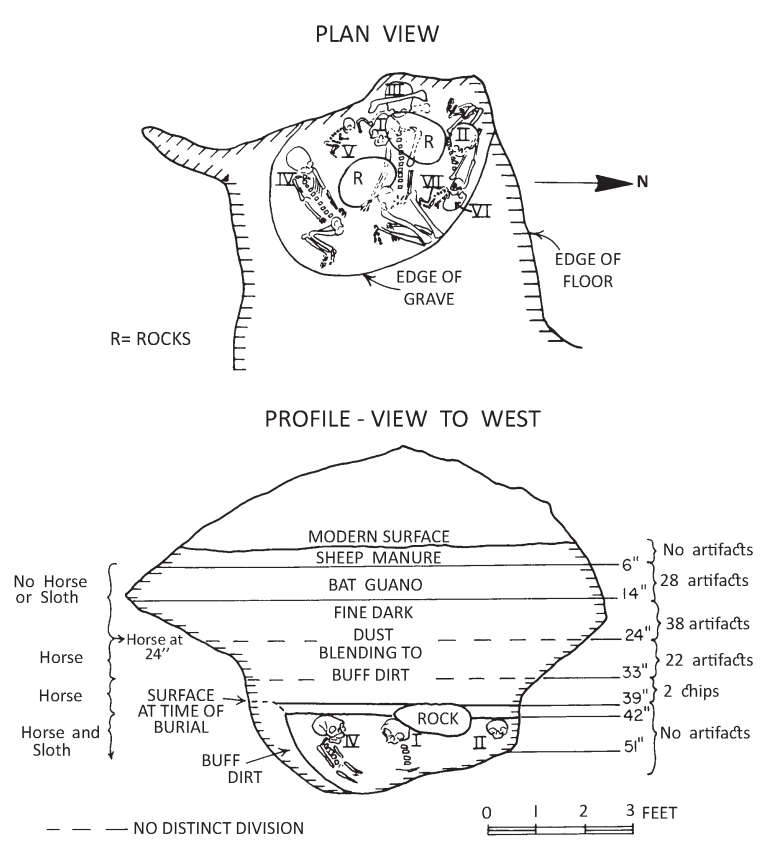

Fig. 3. A- Disposición de los individuos dentro de la superficie cavada para la inhumación; BPerfil de la excavación del entierro en la cámara interior de la cueva (Bird 1988: Fig. 90).

manera superpuesta decúbito lateral con los miembros inferiores semi y completamente flexionados y los miembros superiores extendidos (Fig. 3). No se halló ajuar funerario asociado, pero se encontraron abundantes trazas de pigmento rojo (ocre) en las superficies de los huesos.

El entierro posee tres fechados radiocarbónicos obtenidos directamente de los esqueletos que lo ubican aproximadamente a comienzos del Holoceno tardío. En 1986 el Dr. Clark Larsen envió una muestra (100 gr de bóveda craneana) del individuo CS.1 (99.1/779) a datar por ${ }^{14} \mathrm{C}$ obteniendo dos edades: $3.645 \pm 65$ y $3.755 \pm 65$ años AP. (Tabla 1). Posteriormente, en agosto de 1991 se fechó un fragmento de mandíbula del individuo CS2 (99.1/780) obteniendo una edad de $3.380 \pm$ 70 (Hedges et al. 1992; Tabla 1). Los individuos fueron inhumados sincronicamente, por lo que las diferencias encontradas entre las edades obtenidas para ambos individuos serían inherentes a las diferentes técnicas utilizadas por los laboratorios. 
Tabla 1. Fechados $\mathrm{C}^{14}$ disponibles para Cerro Sota.

\begin{tabular}{|c|c|c|c|c|c|c|}
\hline \multicolumn{7}{|c|}{ CUEVA CERRO SOTA } \\
\hline Procedencia & Unidad & Profundidad & Edad & Técnica & Muestra & Referencia \\
\hline Cámara & $C 4 / 5$ & $>100 \mathrm{~cm}$ & $3.645 \pm 65$ & AA-7788 & $779 . C S .1^{*}$ & \\
interior & $\mathrm{C} 4 / 5$ & $>100 \mathrm{~cm}$ & $3.755 \pm 65$ & AA-7789 & $779 . \mathrm{CS} 1^{*}$ & \\
& $\mathrm{C} 4 / 5$ & $>100 \mathrm{~cm}$ & $3.380 \pm 70$ & OxA-2850 & 780. CS.2.** & Hedges et al. 1992 \\
\hline
\end{tabular}

*Fechado de 100 gr de bóveda craneana de CS1 (99.1/779); **Fragmento de mandíbula de CS2 (99.1/780).

Anteriormente, J. Bird había ubicado al entierro a fines del Período I de cueva Fell alrededor del $10.080 \pm 160$ AP. debido a la presencia de fauna extinguida por encima y en el relleno de la estructura de entierro (Bird 1988: 212, 217). Con estos fechados se descartó la asociación entre estas poblaciones y la fauna pleistocénica de comienzos del Holoceno. La presencia de huesos de fauna extinguida y un fragmento de piel de Hippidion saldiasi arriba de la inhumación se explica por la modalidad de entierro antes detallada, donde el sedimento retirado en la excavación realizada para formar la cavidad donde se colocaron los cuerpos se usó para cubrir la estructura, arrastrando los restos de fauna antiguos que contenían, los cuales quedaron reubicados estratigráficamente.

Los esqueletos de Cerro Sota se estudiaron con diferentes objetivos. Un estudio descriptivo preliminar del material de Cerro Sota fue realizado por el Dr. Charles Lester y revisado por el Dr. Ian Tattersall de la División de Antropología (AMNH) (Bird 1988). Por otro lado se inspeccionó la morfología dental que sugirió, a partir de una homogeneidad morfológica, la menor distancia biológica de las poblaciones aborígenes del norte de Asia y de americanos de tiempos recientes con los individuos de Cerro Sota (Turner y Bird 1981). Un análisis de afinidad morfológica craneal de diferentes poblaciones humanas americanas tempranas incluyó un cráneo de Cerro Sota y, de acuerdo con los resultados del análisis multivariado aplicado, se identificó que el mismo presentaba una morfología mongoloide (Neves et al. 1999 a,b). En otro trabajo morfométrico se describió la forma de los cráneos y de algunos huesos largos de tres individuos (CS.1, CS.2 y CS.3; Soto-Heim 1994) y, entre otras características, este trabajo define que desde la vista superior, los cráneos presentan un contorno ovoide o romboide que se estrecha hacia el posterior del cráneo y que los esplacnocráneos exhiben mesognatismo (proyección del rostro) con prominencia de la región maxilar (prognatismo) en CS. 2 y un perfil plano a la altura del maxilar (ortognatismo) en CS.1. En general la forma grácil y redondeada definida para los huesos largos se correspondería con lo esperado para individuos femeninos que conforman la submuestra estudiada (Soto-Heim 1994).

Algunos aspectos paleodietarios de los individuos de Cerro Sota pudieron ser analizados a partir del análisis de isótopos estables (Barberena 2002). El valor de $\delta^{13} \mathrm{C}$ colágeno de -19.9 obtenido para CS.2 fechado en forma directa por ${ }^{14} \mathrm{C}$ (Hedges et al. 1992) expuso un tipo de dieta terrestre para el mismo y, más allá de la vinculación social y/o biológica que lo relaciona con los otros individuos del entierro, esta determinación se hizo extensible a todo el grupo estudiado. Cabe mencionar que Cerro Sota se encuentra a más de $50 \mathrm{Km}$ de distancia de las costas marinas (atlántica, pacífica y del estrecho de Magallanes) y en la misma franja espacial (50-100 $\mathrm{Km}$ de la costa) se localizaron otras muestras de cazadores recolectores con dieta terrestres y mixtas (Barberena 2002).

En el presente trabajo se pretende profundizar el estudio bioarqueológico del sitio Cerro Sota incluyendo todos los restos óseos (elementos completos y fragmentos del esqueleto axial y apendicular presentes), con el objeto de obtener información detallada y cuantificada de los especímenes presentes por individuo, los procesos tafonómicos identificados en los huesos y los indicadores patológicos. A su vez, se relaciona la información obtenida en este sitio con otro con modalidad de entierro y cronología similar hallada en el área y del que se cuenta con información detallada del contexto de excavación (Orejas de Burro 1; L'Heureux y Barberena 2008).

\section{EL ENTIERRO MÚLTIPLE DE CERRO SOTA}

Los restos humanos de Cerro Sota se encuentran actualmente depositados en la División de Antropología del Museo Americano de Historia 
Natural de Nueva York (AMNH). La colección tiene los números 99.1/776 a 99.1/785 del catálogo "South Chile Muesum Expedition - J. Bird". A estos debe sumársele dos especímenes (uñas de pulgares) almacenadas con los restos óseos de fauna (catálogo "Bird cave sites. Archaeological materials" 41.1/2018). De acuerdo con la información brindada por J. Bird (1988: 210) en la estructura de entierro se hallaron siete individuos inhumados simultáneamente, tres adultos femeninos y cuatro subadultos de sexo indeterminado. En el análisis de laboratorio realizado por los autores se estudiaron 444 especímenes identificando 9 individuos en el conjunto óseo humano de Cerro Sota. De estos, seis proceden del entierro (Número de Especíenes Identificados -NISP-: 439) y tres de la excavación de la cámara interior aproximadamente a 38,10/60,95 $\mathrm{cm}$ de profundidad por fuera de la estructura de entierro (NISP: 3; Tabla 2). Este material adicional se encuentra compuesto por una mandíbula de un adulto (99.1/776), un fragmento de maxilar de un subadulto (99.1/777) y por una mandíbula de otro individuo subadulto (99.1/778). Bird (1988: 213) menciona la presencia de un fémur perteneciente a este último individuo subadulto que no se halló en el conjunto estudiado y se encontraría perdido. Junto con este material adicional se consideran las uñas antes mencionadas (41.1/2018) que no se adjudican a ninguno de los individuos.

\section{LOS INDIVIDUOS DE CERRO SOTA. INFORMACIÓN BIOARQUEOLÓGICA}

Cerro Sota 1 (99.1/779; CS.1). Este individuo se encuentra muy incompleto y se compone sólo por ocho elementos del cráneo: calvaria (reconstruida), mandíbula y seis fragmentos de coronas/raíces de piezas dentales aisladas. La fragmentación posdepositacional de la calvaria es elevada (NISP: 82) completando en total un NISP de 89 con los otros elementos hallados. Los 100 gr de bóveda craneana enviados en 1986 por el Dr. Clark Larsen para datar en el laboratorio Oxford Radiocarbon Accelerator Unit (Tabla 1) se cuantificaron como un especímen. La fragmentación es elevada debido a la presencia de misceláneas indeterminadas y de los fragmentos de occipital, temporal, de frontal indeterminados y del parietal derecho y petroso izquierdo que no se pudieron ensamblar o que se despegaron posteriormente. Esto último concuerda con la presencia de un fragmento de maxilar y de temporal derecho aislados con abundante pegamento adherido. La edad y el sexo de CS.1 se estimó a partir de la obliteración de las suturas craneales (Meindl y Lovejoy 1985) y de los rasgos morfológicos en el esplacnocráneo y en la mandíbula (Buikstra y Ubelaker 1994), definendo que se trata de un individuo femenino de más de 45 años de edad (Tabla 2). Estas variables se pudieron observar debido a los trabajos de reconstrucción de

Tabla 2. Estimación sexual y etarea de los individuos. Elementos y especímenes representados por esqueleto.

\begin{tabular}{|c|c|c|c|c|c|c|}
\hline \multicolumn{7}{|c|}{ CUEVA CERRO SOTA } \\
\hline \multicolumn{2}{|c|}{ INDIVIDUO } & \multirow[t]{2}{*}{ SEXO } & \multirow{2}{*}{\multicolumn{2}{|c|}{ EDAD }} & \multirow[t]{2}{*}{ NISP } & \multirow[t]{2}{*}{ MNE } \\
\hline $\mathbf{N}^{\circ}$ & Inventario & & & & & \\
\hline CS.1 & $99.1 / 779$ & $\mathrm{~F}$ & Adulto medio & 45-50 años & 89 & 8 \\
\hline CS.2 & $99.1 / 780$ & $\mathrm{~F}$ & Adulto medio & 35-50 años & 4 & 3 \\
\hline CS. 3 & $99.1 / 781$ & $\mathrm{~F}$ & Adulto medio & 35-40 años & 92 & 4 \\
\hline CS.4 & $99.1 / 782$ & $\mathrm{~F}$ ? & Subadulto & $5 \pm 1,5$ años & 130 & 4 \\
\hline CS.5 & $99.1 / 783$ & $F$ ? & Subadulto & $\geq 5 \pm 1,5$ años & 49 & 5 \\
\hline CS.6 & $99.1 / 784 / 5$ & INDET & Subadulto & $6 \pm 2$ años & 75 & 9 \\
\hline CS.8 & 99.1/776* & $\mathrm{M}$ & Adulto medio & 35-40 años & 1 & 1 \\
\hline CS.9 & $99.1 / 777^{*}$ & INDET & Subadulto & $4 \pm 1$ años & 1 & 1 \\
\hline CS.10 & $99.1 / 778^{*}$ & M & Subadulto & $11 \pm 2,5$ años & 1 & 1 \\
\hline INDET & $41.1 / 2018^{*}$ & INDET & INDET & INDET & 2 & 2 \\
\hline
\end{tabular}

* Restos óseos humanos adicionales hallados en la cámara interior entre los 38,10 y 60,95 cm; NISP: número de especíenes identificados; MNE: número mínimo de elementos. 


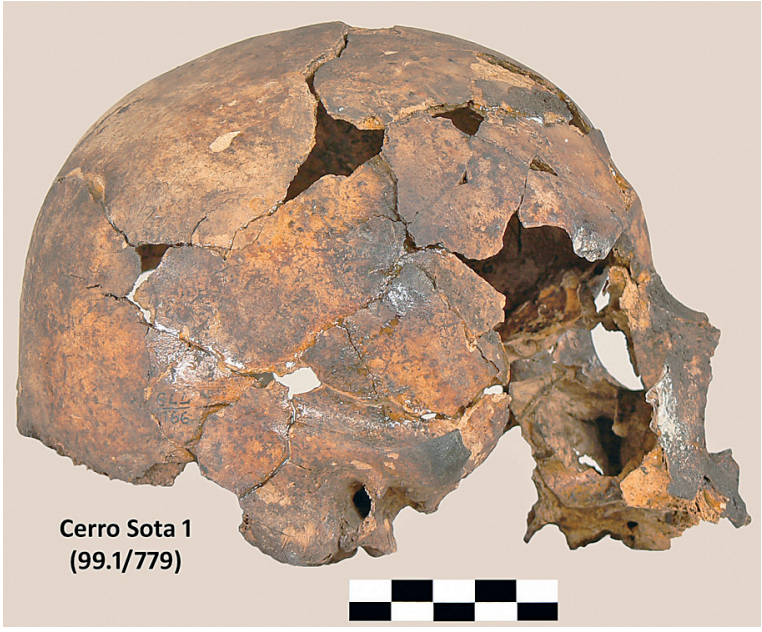

Fig. 4. Vista lateral derecha de la calvaria de CS.1. Se observa una elevada fragmentación posdepositacional y el trabajo de reconstrucción de la bóveda craneana.

Presenta una mínima evidencia de alteración térmica en el borde fragmentado del arco cigomático derecho.

la bóveda craneana (Fig. 4). El estado de conservación general de la calvaria es de regular a malo con mínima evidencia de alteración térmica. Por el contrario, la mandíbula se encuentra en buen estado con termoalteración sólo en el brode fragmentado de la rama derecha (Fig. 5).

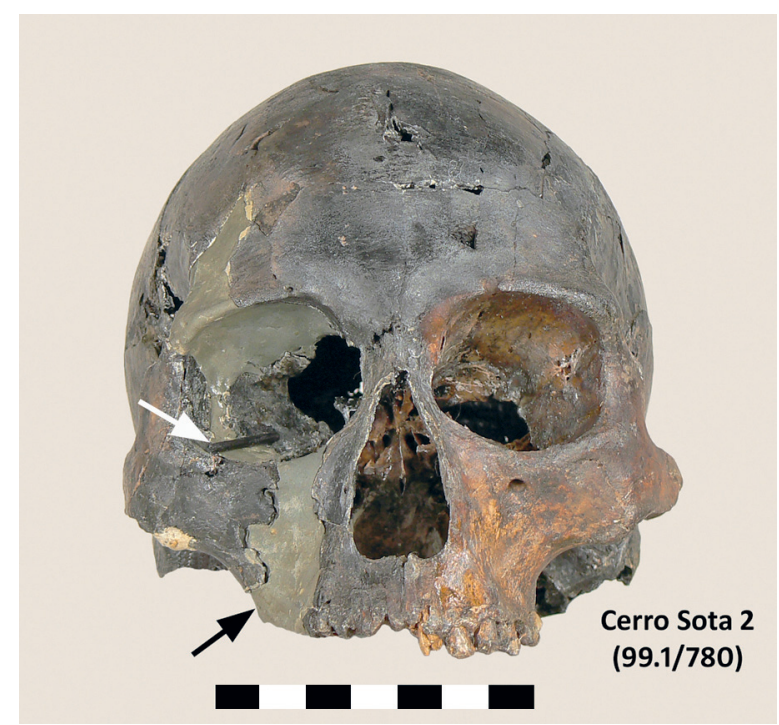

Fig. 6. Vista frontal de la calota de CS.2 reconstruida con pegamento, barillas plásticas (interior de la bóbeda) y con plastilina industrial para reemplazar los sectores del maxilar y de las órbitas ausentes. La extensa alteración térmica en la calvaria no afecta el sector izquierdo del maxilar, frontal (interior órbita) y temporal izquierdo.

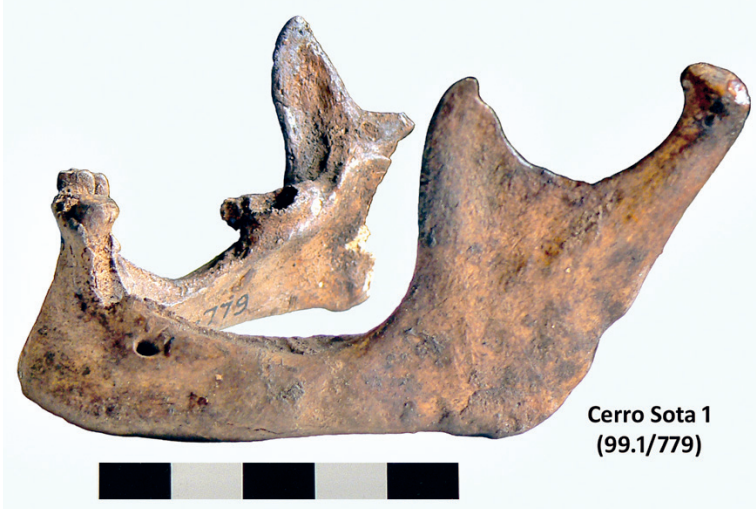

Fig. 5. Mandíbula de CS.1. Se observa la reabsorción total de la tabla alveolar (pérdida dental antemortem: PDAM) en el sector de los incisivos centrales y de las piezas posteriores con pérdida de la altura de la tabla alveolar. $\mathrm{El} \mathrm{M}_{3}$ derecho, perdido posdepositacionalmente (PDPM), presenta el alvéolo abierto y vacío. La acción térmica sólo se observa en el brode fragmentado de la rama derecha.

Cerro Sota 2 (99.1/780; CS.2). Este individuo se encuentra compuesto por tres elementos: calvaria, mandíbula y dos fragmentos de húmero izquierdo (NISP: 4; Tabla 2). El sexo y la edad del individuo se estimó a partir de los rasgos craneales (Buikstra y Ubelaker 1994; Meindl y Lovejoy

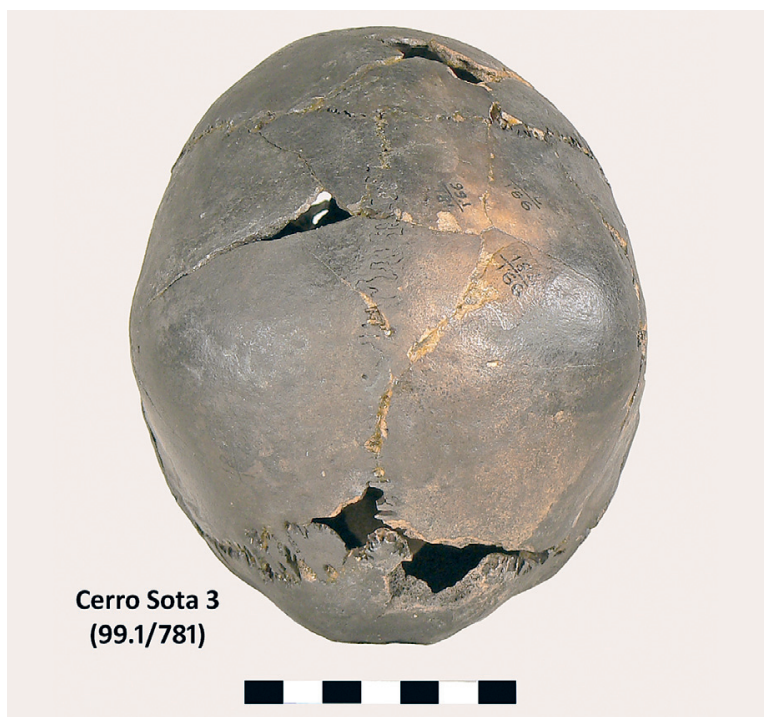

Fig. 7. Vista superior de la calvaria de CS.3. Es el elemento más afectado por combustión con alteración térmica casi completa con excepción de un sector del parietal derecho. En los bordes de las fracturas frescas del hueso cortical se observa que la combustión involucra sólo la tabla externa. 
1985), identificando un individuo femenino adulto medio (35-50 años). El estado de conservación de la calvaria es malo. Se encuentra remontada con pegamento y su forma fue reconstruida mediante el uso de barillas plásticas (interior de la bóbeda) y de plastilina industrial para reemplazar la sectores del maxilar y de las órbitas ausentes (Fig. 6). La extensa alteración térmica en la calvaria no afecta todo el elemento, quedando el sector izquierdo del maxilar, frontal (interior órbita) y temporal izquierdo sin rastros de combustión (Fig. 6). El húmero, con buen estado de conservación, registra alteración térmica parcial y la epífisis distal (reconstruida) se encuentra separada de la diáfisis. El fragmento de mandíbula correspondiente a CS. 2 se envió al Laboratory of Isotope Geochemistry at the University of Arizona para su datación por AMS.

Cerro Sota 3 (99.1/781; CS.3). Este individuo se compone de cuatro elementos (calvaria, dos huesecillos del oído y el radio izquierdo; Tabla 2) que, por la elevada fragmentación, están representados por 92 especímenes, principalmente de misceláneas de la calvaria (NISP: 87). CS.3 es un individuo adulto medio de 35-40 años de sexo femenino (Buikstra y Ubelaker 1994; Meindl y Lovejoy 1985). El estado de conservación de la calvaria (reconstruida y con alteración térmica casi completa con excepción de un sector del parietal derecho; Fig. 7) es regular/ malo. El radio se encuentra representado por dos fragmentos debido a un corte intencional a la altura de la metáfisis proximal en buen estado y sin alteración térmica. Este fue el único individuo adulto del que se tomaron las longitudes de los huesos largos in situ (Bird 1988: 212). De acuerdo con estas medidas, la estatura en vida de CS.3 puede ser estimada aproximadamente en $154,49 \mathrm{~cm}$ por la longitud máxima del fémur izquierdo $(38,10 \mathrm{~cm})$, de 159,78 $\pm 4,25 \mathrm{~cm}$ por el húmero izquierdo $(28,58 \mathrm{~cm}) \mathrm{y}$ $167,42 \pm 4,6 \mathrm{~cm}$ de acuerdo con la medida del radio tomada por J. Bird $(24,13 \mathrm{~cm})$ o de $166,64 \pm 4,6$ $\mathrm{cm}$ a partir de la longitud de este mismo elemento obtenida por uno de los autores (GLL) en el laboratorio $(23,91 \mathrm{~cm})$. Estas estimaciones de la estatura máxima en vida se hicieron a partir de las fórmulas de regresión derivada de las longitudes totales de los huesos largos de mongoloides masculinos (Trotter 1970 en Steele y Bramblett 1988).
Cerro Sota 4 (99.1/782; CS.4). Está compuesto por 130 especímenes de cuatro elementos (calvaria, mandíbula y dos vértebras cervicales; Tabla 2). CS.4 es un individuo que en principio fue identificado como subadulto de ca. 8 años de edad (Bird 1988: 216), pero en este estudio se observaron rasgos de madurez, erupción y reemplazo dental correspondientes a un niño de menor edad, ca. $5 \pm$ 16 meses (Ubelaker 1989). Esta estimación se sustenta en que los gérmenes de molares hallados son de primeros molares permanentes no erupcionados, y no corresponderían a coronas en formación de segundos molares, donde residiría la diferencia en la estimación etarea. La mandíbula, con alteración térmica, tiene rasgos morfológicos semejantes a los identificados en individuos infantiles femeninos (Schutkowski 1993).

Cerro Sota 5 (99.1/783; CS.5). Este individuo se compone de 49 fragmentos (Tabla 2) de cinco elementos, calvaria (44 fragmentos: parietales, occipital, frontal, malares no fusionados e indeterminados), costilla distal, mandíbula y dos gérmenes de primeros molares permanentes aislados. El fragmento de mandíbula (tabla alveolar con alvéolos sin piezas dentales) presenta alteración térmica y pocos rasgos diagnósticos para estimar el sexo y edad. Comparativamente con CS.4, puede decirse que este individuo es de menor tamaño y presenta rasgos morfológicos semejantes, por lo que se asume es del mismo sexo con una edad semejante o menor. Con el número de catálogo 99.1/783 se registra también una segunda falange del pie entera en buen estado de conservación. Este elemento, que debe proceder de alguno de los individuos adultos, no se consideró en la cuantificación de las variables de ninguno de los individuos.

Cerro Sota 6 (99.1/784/785; CS.6). Es un individuo subadulto de aproximadamente $6 \pm 2$ años conformado por 75 especímenes de nueve elementos (67 fragmentos y misceláneas de calvaria, una mandíbula y siete dientes aislados -seis gérmenes de dientes permanentes y un $\mathrm{m}_{2}$ deciduo-; Tabla 2) con un estado regular de conservación. Presenta ocre y alteración térmica completa/parcial en fragmentos del occipital, parietal y temporal izquierdo y en la mandíbula y dientes aislados. Este individuo 


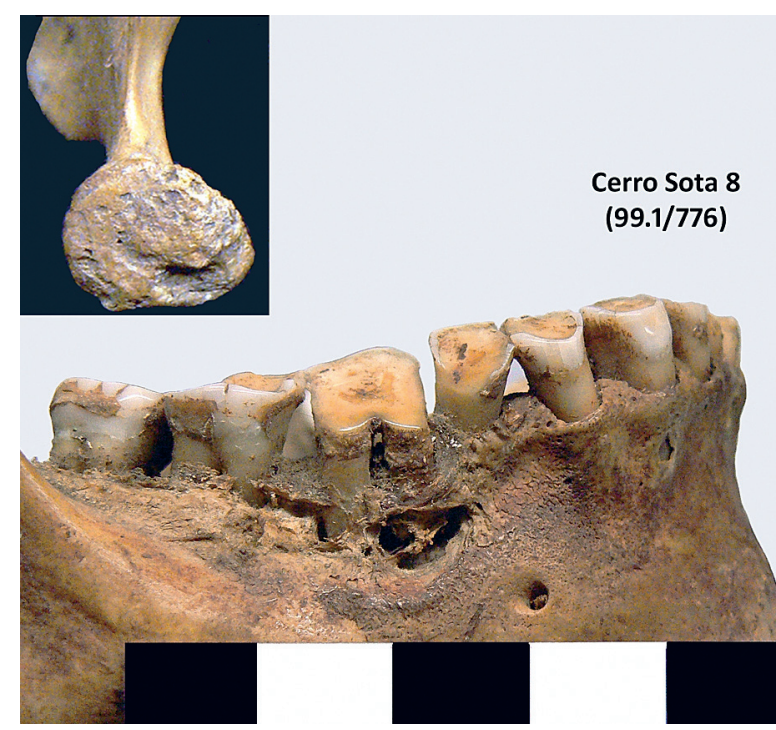

Fig. 8. Resto humano adicional. El espécimen 99.1/776 (CS.8) es una mandíbula de un individuo adulto medio masculino sin alteración térmica y con rastros de ocre. Registra desgaste dental avanzado en dientes anteriores y molares asociadas con modificaciones fisiológicas: tilting. Las patologías presentes son abscesos complejos a la altura de los primeros molares y osteoartrosis en el cóndilo mandibular izquierdo. Es abundante la presencia de cálculo dental en todas las piezas dentales.

se conforma con los especímenes del individuo identificado como 99.1/784 (NISP: 40) y de otro catalogado como 99.1/785 (NISP: 35). Anteriormente Bird (1988: 217) había sugerido que los restos del individuo subadulto ingresado como 99.1/784 pertenecían al 99.1/785, pero igualmente fueron cuantificados como dos diferentes (Bird 1988). El séptimo individuo, otro subadulto, se habría extraviado (99.1/785; CS.7).

\section{Individuos Adicionales (CS.8, CS.9 y CS.10)}

Cerro Sota 8 (99.1/776; CS.8). Es una mandíbula entera de un individuo masculino adulto de más de 35 años de edad con 15 piezas dentales in situ (Tabla 2). Este elemento se encuentra en buen estado de conservación, sin alteración térmica y con rastros de ocre (Fig. 8).

Cerro Sota 9 (99.1/777; CS.9). Es un fragmento de maxilar derecho (Tabla 2) con dos molares deciduos en oclusión con bajo desgaste. De acuerdo con los estadios de erupción y reemplazo dental se estima que se trata de un subadulto de $4 \pm 1$ años

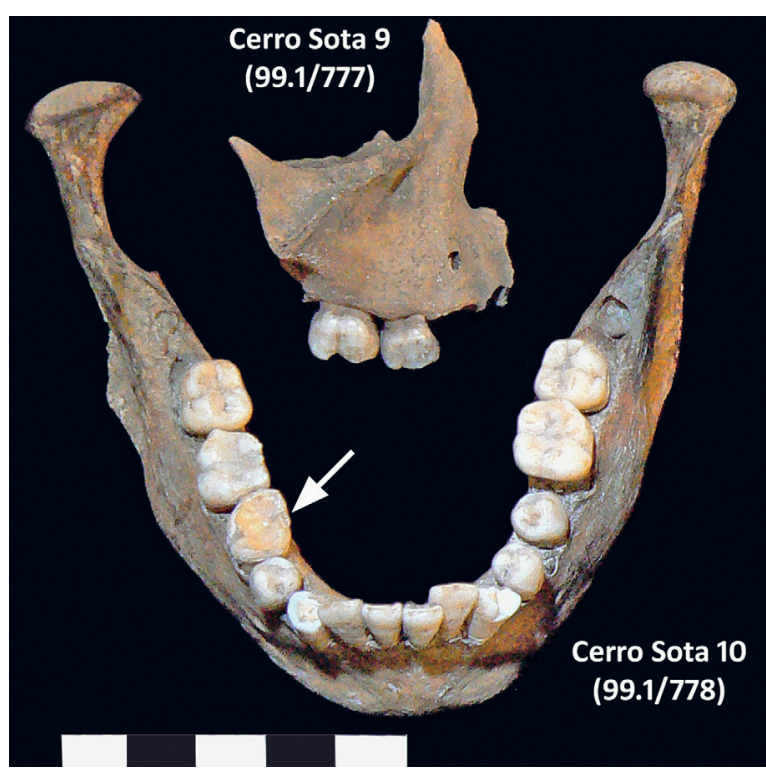

Fig. 9. Restos humanos adicionales. A- Espécimen 99.1/777 (CS.9): fragmento de maxilar derecho de un subadulto con dos molares deciduos en oclusión y sin alteración térmica. B- Mandíbula de otro subadulto (99.1/778; CS.10) sin alteración térmica y con rastros de ocre y tejido adherido. Los primeros molares permanentes presentan bajo desgaste y todavía retiene en oclusión el primer molar deciduo derecho con elevado desgaste.

de edad (Ubelaker 1989; Fig. 9). Este elemento se encuentra en buen estado de conservación, sin alteración térmica y con algunas astillas asociadas con vestigios de ocre.

Cerro Sota 10 (99.1/778; CS.10). Es una mandíbula de un subadulto masculino de aproximadamente 11 años \pm 30 meses (Ubelaker 1989; Fig. 9). Este elemento se encuentra en buen estado de conservación, sin alteración térmica, con ocre y tejido adherido. Junto con estos elementos adicionales se consideran las uñas de pulgares con ocre depositadas con el material óseo de fauna (41.1/2018) (Tabla 2).

J. Bird menciona la presencia de siete individuos en el entierro, tres adultos, tres niños y un infante (Bird 1988: 212). Como se consideran infantes a aquellos subadultos entre 0 y 3 años (Buikstra y Ubelaker 1994), se observa que la identificación de un infante en la estuctura de entierro no es apropiada debido a que en la muestra estudiada no se identificaron individuos menores de ca. $5 \pm 1,5$ años. De todos modos no se puede conocer si este individuo infantil se refería a CS.7 (99.1/785), el subadulto extraviado. 
Tabla 3. Representación de piezas dentales y modificaciones fisiológicas y patológicas de la cavidad bucal en los individuos de Cerro Sota.

\begin{tabular}{|c|c|c|c|c|c|c|c|c|c|}
\hline & & \multicolumn{5}{|c|}{$\begin{array}{l}\text { REPRESENTACIÓN DE } \\
\text { PIEZAS DENTALES }\end{array}$} & \multicolumn{3}{|c|}{$\begin{array}{c}\text { MODIFICACIONES FISIOLÓGICAS } \\
\text { Y PATOLÓGICAS }\end{array}$} \\
\hline \multicolumn{2}{|c|}{ CERRO SOTA } & DIENTES & IN SITU & AISLADOS & PDPM & PDAM & ABSCESOS & TILTING & HIPOPLASIA \\
\hline \multirow[t]{2}{*}{ CS.1 } & M. superior & 6 & 0 & 6 & 0 & 0 & 0 & 0 & \begin{tabular}{|l|}
0 \\
\end{tabular} \\
\hline & Mandíbula & 3 & 3 & 0 & 6 & 7 & 1 & 0 & 0 \\
\hline \multirow[t]{2}{*}{ CS.2 } & M. superior & 9 & 9 & 0 & 7 & 0 & 0 & 0 & 0 \\
\hline & Mandíbula & -- & -- & -- & -- & -- & -- & -- & -- \\
\hline \multirow[t]{2}{*}{ CS.3 } & M. superior & 0 & 0 & 0 & Indet. & 2 & 0 & 0 & 0 \\
\hline & Mandíbula & -- & -- & -- & -- & -- & -- & -- & -- \\
\hline \multirow[t]{2}{*}{ CS.4 } & M. superior & 2 & 0 & 2 & 10 & 0 & 0 & 0 & 0 \\
\hline & Mandíbula & 6 & $6^{*}$ & 0 & 4 & 0 & 0 & 0 & 0 \\
\hline \multirow[t]{2}{*}{ CS.5 } & M. superior & -- & -- & -- & -- & -- & -- & -- & -- \\
\hline & Mandíbula & 0 & 0 & 2 & 7 & 0 & 0 & 0 & 0 \\
\hline \multirow[t]{2}{*}{ CS.6 } & M. superior & 7 & $5^{*}$ & 2 & 7 & 0 & 0 & 0 & 0 \\
\hline & Mandíbula & 4 & 1 & 3 & 10 & 0 & 0 & 0 & 0 \\
\hline \multirow[t]{2}{*}{ CS.8 } & M. superior & -- & -- & -- & -- & -- & $\overline{--}$ & -- & -- \\
\hline & Mandíbula & 16 & 16 & 0 & 0 & 0 & 2 & 2 & 0 \\
\hline \multirow[t]{2}{*}{ CS.9. } & M. superior & 2 & 2 & 0 & 3 & 0 & 0 & 0 & 0 \\
\hline & Mandíbula & -- & -- & -- & -- & -- & -- & -- & -- \\
\hline \multirow[t]{2}{*}{ CS.10 } & M. superior & -- & -- & -- & -- & -- & -- & -- & -- \\
\hline & Mandíbula & 14 & 14 & 0 & 0 & 0 & 0 & 0 & 4 \\
\hline \multicolumn{2}{|r|}{ TOTAL } & 69 & 56 & 15 & 54 & 9 & 3 & 2 & 4 \\
\hline
\end{tabular}

- Restos humanos adicionales; PDPM: dientes perdidos postmortem; PDAM: dientes perdidos antemortem; --: sin elemento (maxilar superior o mandíbula); "raíces in situ y coronas fragmentadas posdepositacionalmente; _gérmenes no erupcionados.

\section{MODIFICACIONES FISIOLÓGICAS Y PATOLÓGICAS}

A pesar que la representación esqueletal se encuentra fundamentalmente compuesta por calvarias y mandíbulas, la representación de dientes es muy baja. Se encontró el 32,46\% del total de dientes esperables para los elementes presentes en los seis individuos del entierro (NISP: 37; Tabla 3). Esto se debe a que muchas de las calvarias no se acompañan de sus respectivas mandíbulas (y viceversa), los elementos presentes se hallan muy fragmentados y por la elevada prevalencia de pérdidas posmortem de piezas dentales o PDPM (44,74\%; Tabla 4).

Respecto de las modificaciones fisiológicas bucales, sólo se pudo observar el desgaste dental en algunas piezas de dos individuos adulltos del entiero (33,33\%). En CS.1 las piezas registradas en el maxilar

Tabla 4. Desgaste oclusal (Scott 1979; Smith 1984) de los individuos con dientes in situ o aislados observables. Se promedian los valores obtenidos de piezas bilaterales presentes.

\begin{tabular}{|c|c|c|c|c|c|c|c|c|c|c|}
\hline & & \multicolumn{9}{|c|}{ Maxilar Superior } \\
\hline \multicolumn{2}{|c|}{ CATEGORÍA EDAD } & AÑOS & M3 & M2 & M1 & Pm2 & Pm1 & C & I2 & I1 \\
\hline CS.2 & ADULTO MEDIO & $35-50$ & $32 ?$ & 34 & 38 & $6 ?$ & $6 ?$ & 7 & 7 & Indet. \\
\hline${\mathrm{CS} .9^{\circ}}^{\circ}$ & SUBADULTO & $4 \pm 1$ & -- & -- & 4 & -- & -- & -- & -- & -- \\
\hline \multicolumn{11}{|c|}{ Mandíbula } \\
\hline \multicolumn{2}{|c|}{ CATEGORÍA EDAD } & AÑOS & M3 & M2 & M1 & Pm2 & Pm1 & $\mathrm{C}$ & I2 & I1 \\
\hline CS.1 & ADULTO MEDIO & $45-50$ & -- & -- & -- & -- & -- & 8 & 8 & -- \\
\hline CS.8 & ADULTO MEDIO & $35-40$ & 27,5 & 36 & 39 & 7 & 6,5 & 7 & 7 & 8 \\
\hline CS.9. & SUBADULTO & $4 \pm 1$ & & 4 & 4 & & & & & \\
\hline CS.10 & SUBADULTO & $11 \pm 2,5$ & Encap. & 4 & 6 & 36 & 2 & Indet. & 2 & 3 \\
\hline
\end{tabular}

-Restos humanos adicionales; En negrita: dientes deciduos; --: ausente; ?: valores dudosos por fragmentación del esmalte; Encap: molar encapsulado no erupcionado. 
son fragmentos de raíces y coronas aisladas (N: 6). En la mandíbula se observa la reabsorción total de la tabla alveolar en el sector de los incisivos centrales, del incisivo lateral izquierdo y de los premolares y molares denotando la pérdida dental antemortem (PDAM) de estas piezas con excepción del $\mathrm{M}_{3}$ derecho, que presenta el alvéolo abierto por lo cual se infiere que es el único molar in situ al momento de muerte y que se perdió posdepositacionalmente (Fig. 5; Tabla 3). Los únicos tres dientes anteriores en oclusión (segundo incisivo derecho y caninos derecho e izquierdo) presentan un desgaste dental máximo (8; Smith 1984; Tabla 4).

CS. 2 presenta problemas en la evaluación del grado de desgaste por la fragmentación posdepositacional del esmalte. Esta variable sólo pudo registrarse sin inconvenientes en cuatro piezas superiores (Tabla 4) y por la fractura del esmalte el desgaste se obtuvo con proyección en tres dientes. En general el desgaste es elevado en dientes anteriores (6 y 7; Smith 1984) y molares (e.g. $38 \mathrm{M}^{1}$; Scott 1979), acorde con lo esperado para cazadores-recolectores de más de 30 años.

En el resto de los individuos del entierro sólo se pudo obtener información acerca de la representación dental, y procesos fisiológicos y patológicos alveolares (Tabla 3). CS.3 exhibe fragmentos aislados del maxilar con alvéolos abiertos (pérdida dental posmortem -PDPM-) y completamente reabsorbidos (pérdida dental antemortem -PDAM-; Tabla 3). El fragmento de maxilar no fusionado de CS.4 no presenta piezas dentales en oclusión y sólo dos gérmenes de $\mathrm{M}^{1}$ permanente no erupcionados aislados. La mandíbula registra la corona fragmentada de un $\mathrm{m}_{2}$ izquierdo deciduo y las raíces (coronas perdidas posmortem de piezas deciduas) del $\mathrm{m}_{1}, \mathrm{~m}_{2}, \mathrm{pm}_{2}$ izquierdo y $\mathrm{pm}_{2}$ y $\mathrm{m}_{1}$ derecho in situ. En general, para CS.4 la PDPM es elevada (70\%; Tabla 3).

CS. 5 registra sólo dos gérmenes de primeros molares permanentes aislados, que podrían ser inferiores debido a que este individuo sólo presenta un fragmento de mandíbula (tabla alveolar con alvéolos sin piezas dentales). Más del 60\% de los dientes de CS.6 se perdieron posmortem. En el maxilar se registran dos piezas aisladas (gérmenes del primer incisivo izquierdo y del segundo molar derecho) y cinco in situ donde tres son fragmentos de raíces y dos gérmenes encapsulados (segundo molar izquierdo $e$ incisivo derecho permanenetes). La mandíbula no presenta dientes en oclusión y sólo cuenta con el segundo molar permanente izquierdo encapsulado in situ y tres piezas aisladas (primer molar deciduo y los gérmenes del canino derecho y del primer molar izquierdo permanentes).

Por encontrarse en mejor estado de conservación, los elementos adicionales presentan buenas condiciones para la evaluación del grado de desgaste y otros procesos fisiológicos y patológicos. En la tabla 4 se observa que la mandíbula de CS.8 registra un desgaste dental avanzado (e.g. 7 y 8 en dientes anteriores; Smith 1984 y 40 y 39 en $M_{1}$; Scott 1979) esperable en edades avanzadas. Como consecuencia de este proceso fisiológico originado por el desgaste severo, se registra un cuadro que comprende tanto modificaciones patológicas: la presencia de dos abcesos complejos (sensu Clarke y Hirsch 1991) a la altura de los primeros molares (Fig. 8; Tabla 3) y osteoartrosis en el cóndilo mandibular izquierdo, como modificaciones fisiológicas: dislocación de los ápices de las raíces en dirección lingual y de las coronas hacia bucal en los primeros molares (tilting; Clarke y Hirsch 1991). Esta dislocación posibilitó que los primeros molares continuaran en función y no se perdieran en vida a pesar de la pérdida de sostén óseo alveolar producto los abcesos complejos que los afectaron (Fig. 8).

La presencia de porosidad y pérdida de la morfología normal del cóndilo izquierdo denota una patología degenerativa activa en la articulación temporo-mandibular. A su vez es abundante la presencia de cálculo dental en las caras bucales y linguales de piezas anteriores y posteriores (grados 1 y 2; Buikstra y Ubelaker 1994).

El fragmento de maxilar derecho de CS.9 presenta dos piezas dentales deciduas en oclusión (m1 y m2) con bajo desgaste (4; Scott 1979; Tabla 4) y tres alvéolos vacíos (PDPM). Cerro Sota 10 es una mandíbula de subadulto completa (Fig. 9) con los primeros molares permanentes en oclusión con bajo desgaste (6; Scott 1979) y que, además, retiene todavía el primer molar deciduo derecho con elevado desgaste en el espacio del futuro premolar permanente (36; Scott 1979. Tabla 4). Los incisivos centrales y laterales presentan una morfología en pala y evidencia de hipoplasia del esmalte dental (Tabla 3). Las hipoplasias comprenden diferentes disturbios en el desarrollo del esmalte dental debido a la formación anormal de los ameloblastos 
(Huss-Ashmore et al. 1982). Son indicadores patológicos inespecíficos de estrés metabólico agudo (e.g. malnutrición, infección, etc.) que se producen durante la etapa de crecimiento y desarrollo de los individuos.

La baja representación de elementos poscraneales limita la estimación de prevalencias de patologías en el postcráneo. Sin tener en cuenta elementos poscraneales axiales, casi completamente ausentes, el 50\% de los huesos largos presentes entre los individuos adultos (NISP: 2) registra signos de patologías degenerativas: osteoatrosis (Waldrom 2009). Se trata del radio izquierdo de CS.3 que presenta importante porosidad y osteoclastía en la epífisis proximal (Fig. 10). Además en el extremo distal de este elemento se observan espículas óseas (osteofitos) y modificación de la morfología normal de la epífisis. Dentro del conjunto de patologías osteoartrósicas en el postcráneo de los adultos, se encuentra la segunda falange rotulada con el subadulto CS.5 (99.1/783) con osteofitos en la epífisis distal y que no pudo ser asignada a ninguno de los individuos. Además se menciona la presencia de una vértebra lumbar de CS.1 con marcada osteoartrosis (Bird 1988: 213) que actualmente no se encuentra presente en el conjunto óseo de Cerro Sota.

\section{MODIFICACIONES POSDEPOSITACIONALES}

Lamentablemente, debido a que los esqueletos del entierro se encuentran muy incompletos se hace difícil hacer una evaluación representativa de las frecuencias de las variables tafonómicas en los

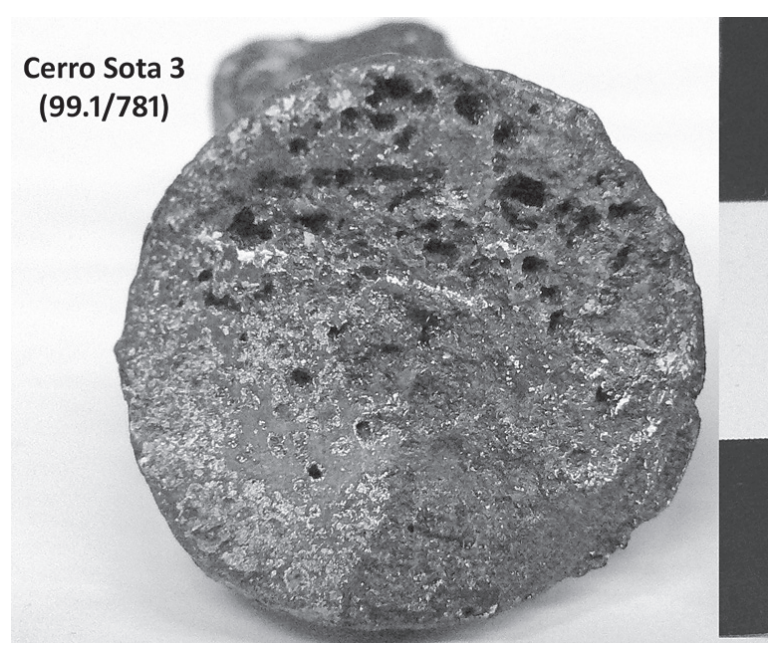

Fig. 10. Epífisis proximal del radio izquierdo de CS.3 con importante porosidad y pérdida ósea (osteoartrosis).

individuos. De todos modos se exponen los datos obtenidos de manera exploratoria (Tabla 5).

Los individuos del entierro estudiados (CS.1 a CS.6; NISP: 439) tienen un estado de conservación general de regular a malo, con el 16,86\% de exfoliación y la casi total fragmentación posdepositacional de los especímenes (95,90\%). Muchas de estas fracturas poseen aspecto de ser nuevas y uno de los elementos exhibe un corte perimetral intencional en una metáfisis proximal realizada en laboratorio (radio izqierdo de CS.3).

En los elementos presentes, principalmente del cráneo, se observó una baja frecuencia de especímenes con tinción con manganeso (3,19\%), rastros de carbonato de calcio $(3,64 \%)$ e improntas de raíces

Tabla 5. Modificaciones tafonómicas registradas en los elementos óseos humanos

\begin{tabular}{|c|c|c|c|c|c|c|c|}
\hline \multicolumn{7}{|c|}{ CUEVA CERRO SOTA } \\
\hline \multirow{3}{*}{ Individuo } & \multicolumn{7}{|c|}{ Variables Tafonómicas } \\
\cline { 2 - 8 } & Manganeso & Exfoliación & Raíces & $\begin{array}{c}\text { Daño } \\
\text { mecánico }\end{array}$ & $\begin{array}{c}\text { Rotura } \\
\text { Posdep }\end{array}$ & CaCo $_{3}$ & $\begin{array}{c}\text { NISP } \\
\text { Huesos }\end{array}$ \\
\hline CS.1 & 9 & 26 & 3 & 1 & 88 & 0 & $\mathbf{8 9}$ \\
CS.2 & 0 & 0 & 0 & 0 & 4 & 0 & 4 \\
CS.3 & 0 & 0 & 0 & 0 & 88 & 3 & $\mathbf{9 2}$ \\
CS.4 & 0 & 1 & 0 & 0 & 122 & 0 & $\mathbf{1 3 0}$ \\
CS.5 & 0 & 35 & 4 & 0 & 47 & 1 & $\mathbf{4 9}$ \\
CS.6 & 5 & 12 & 5 & 3 & 72 & 13 & $\mathbf{7 5}$ \\
\hline CS.8 & 0 & 0 & 0 & 0 & 0 & 0 & $\mathbf{1}$ \\
CS.9. & 0 & 1 & 0 & 0 & 1 & 1 & $\mathbf{1}$ \\
CS.10 & 0 & 1 & 0 & 0 & 0 & 1 & $\mathbf{1}$ \\
\hline TOTAL & 14 & 76 & 12 & 4 & 422 & 19 & $\mathbf{4 4 2}$ \\
\hline
\end{tabular}

-Restos humanos adicionales; $\mathrm{CaCo}_{3}$ : carbonato de calcio; NISP: número de especíenes identificados. 


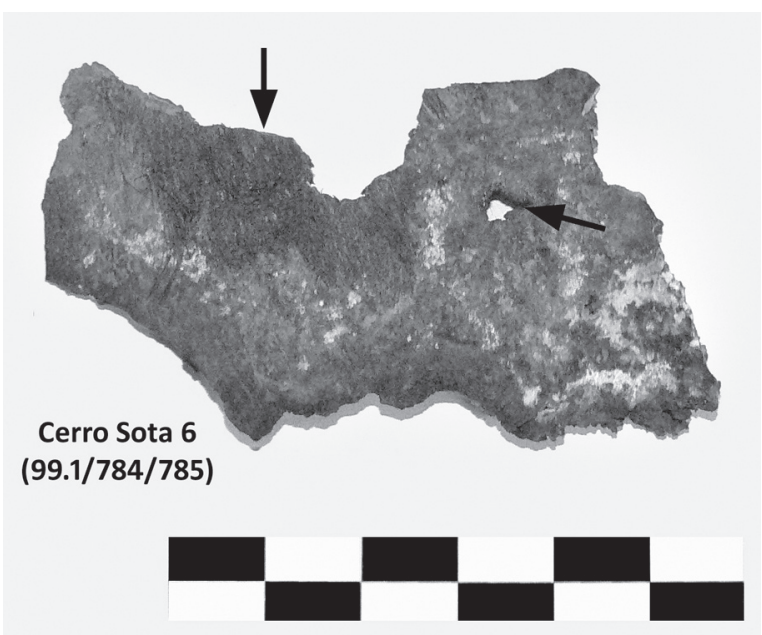

Fig. 11. Fragmento de temporal derecho del individuo subadulto CS.6 que presenta cabellos adheridos teñidos con ocre. Sobre la tabla cortical se observa la presencia de daños mecánicos en forma de pits.

(2,73\%). Se observa la presencia de daños mecánicos en sólo cuatro elementos (bóveda craneana de CS.1 $y$ tres fragmentos de frontal y parietal izquierdo de CS.6). Esta información adquiere relevancia en tanto la información contextual del entierro informa sobre la disposición de rocas volcánicas directamente sobre los cuerpos (Bird 1988: 210) como parte de la inhumación. El contacto de las superficies corticales con las aristas de éstas rocas sería la causa de su formación. Las modificaciones mecánicas se presentaron en su mayoria como pits (Fig. 11) y, en ocasiones, se observaron asociados con hundimiento del tejido cortical, estrías y fisuras radiales.

Los elementos adicionales que conforman a CS.8, CS.9 y CS.10 se encuentran en buen estado de conservación y sólo uno tiene fractura posdepositacional (maxilar de CS.9). También exhiben baja frecuencia de exfoliación y carbonato de calcio. No registran manganeso o improntas de radículas en las suprficies corticales $y$, al hallarse por fuera de la estructura de entierro, no registran daños mecánicos (Tabla 5).

\section{MODIFICACIONES ANTRÓPICAS PREDEPOSITACIONALES}

Todos los individuos del entierro se hallaron asociados con gramíneas, puestas principalmente como superficie de apoyo, y cubiertos con rocas volcánicas (Tabla 6) conformando una particular estructura de inhumación. Los restos adicionales, hallados por fuera de la misma a menor profundidad, estaban aislados sin gramíneas o rocas asociadas.

En la superficie cortical de los elementos presentes en el entierro se observa que los individuos estuvieron en contacto con pigmentos de ocre. La tinción pudo producirse por el tratamiento directo de los cuerpos con pintura, o por haber sido cubiertos o envueltos en cueros pintados durante el rito de inhumación. Por la baja completitud de los esqueletos los datos pueden encontrarse subestimados, igualmente se puede confirmar que el $50 \%$ de los individuos presentaban ocre (Tabla 6), siendo el subadulto CS.5 (> $5 \pm 1,5$ años) el que presentaba la mayor frecuencia de especímenes teñidos (59,18\%), seguido del adulto medio CS.1 (29,55\%) y del individuo CS.6 (6 \pm 2 años) con el 21,33\% de los especímenes con ocre. En este último caso es interesante mencionar que el temporal derecho de este individuo retiene cabellos adheridos teñidos con ocre (Fig. 11) y que, asociado con los fragmentos del parietal izquierdo, se encuentra en un sobre una muestra de cabellos humanos con ocre y carbonato de calcio. Entre los elementos adicionales, las mandíbulas de CS.8 y CS.10 tienen rastros de ocre y el fragmento de maxilar de CS.9 no, aunque algunas astillas asociadas con este elemento registran tintura roja.

Este sitio de entierro tiene características semejantes y diferencias respecto de otros hallados en el área para la misma cronología como el sitio Orejas de Burro 1 (OB1; L'Heureux y Barberena 2008). Tanto Cerro sota como OB1 responden a un mismo patrón de entierro que involucra una inhumación en cueva dentro de una cavidad subcircular excavada con el objetivo de depositar los cuerpos dentro, éstos en posición decúbito lateral con los miembros inferiores flexionados, la disposición de gramíneas entre y por debajo de los individuos y la cobertura del entierro con bloques de roca basáltica. La diferencia en entre estos dos sitios es la presencia de combustión de parte del entierro, que se encuentra sólo en Cerro Sota y que le valió, por décadas, la denominación de sitio con cremación (Bird 1983, 1988).

De los individuos presentes en Cerro Sota, todos presentan algún grado de alteracion térmica en sus superficies corticales (Tabla 6). Esta se exhibe con una variabilidad cromática que va desde una 
mancha efimera oscura hasta la coloración negra casi completa del elemento. Siguiendo los patrones de quemado definidos por Buikstra y Swelge (1989): calcinado (gris, azulado, blanco), smoked (negroahumado) y no quemado, los huesos de Cerro Sota se encontrarían todos dentro de la categoría smoked, con elementos que presentan desde una pequeña mancha oscura difusa (mandíbula de CS.1) hasta un extenso quemado negro oscuro, pero nunca niveles de calcinamiento. De igual modo, el quemado de los elementos mas afectados sólo involucra la capa cortical superficial del hueso, ya que donde se observa cierta fisura o borde de fractura fresca del hueso, el color que aflora debajo es normal (calvaria de CS.3; Fig. 7).

El inividuo con mas especimenes afectados por el fuego es CS.4 (5 \pm 16 meses) con los cuatro elementos que lo reprsentan con alteración térmica completa y/o parcial (Tabla 6). Es interesante el caso de CS.3 (F; 35-40 años), con el 98,91\% de los especimenes quemados, donde tres sus cuatro elementos tienen diferentes estadios de alteración térmica: su calota es el elemento más quemado del conjunto (Fig. 7) pero el radio izquierdo del mismo individuo no registra contacto con el fuego. El resto de los individuos, representados tambien por los cráneos, registran menor alteración térmica siendo moderada a alta en CS.2 (75\%) y CS.5 (67,35\%) y mas baja en CS.1 y CS.6 (Tabla 6).

En una cremación los huesos frescos con tejidos orgánicos blandos presentan un predominio de fracturas transversales con líneas transversas al eje de la diáfisis (mientras que los huesos secos lo hacen longitudinalmente) (Baby 1954; Binford 1963; Reverte 1984-5; Ubelaker 1989). Muchos de los huesos aparecen calcinados (oxidación completa) y exhiben una coloración distintiva blancuzco-azulada además del negro oscuro. También se encuentran combados, lo cual impide la completa reconstrucción de los fragmentos (Schmidt y Symes 2008). Por el contrario, entre los especímenes estudiados sólo se registraron fragmentos con tinción de color negro sobre las superficies corticales y no se observó un patrón específico en la orientación de las fracturas, siendo tanto transversales, longitudinales como sinuosas. Esto se debería a que la elevada fragmentación no respondería completamente a la acción del fuego sino serían posdepositacional en estado seco. Esto se manifiesta en la elevada frecuencia de fragmentos con bordes de fractura fresca posexcavación (ver supra: modificaciones posdepositacionales).

\section{DISCUSIÓN Y CONCLUSIONES}

El tema de si se trata o no de un sitio de cremación se discute en este trabajo en base a la información del contexto de excavación, la definición de cremación, el estado en que se hallaron los fragmentos óseos de los esqueletos y a la comparación con otros sitios con modalidad de entierro y cronología semejante.

Tabla 6. Modificaciones predepositacionales en los elementos óseos humanos.

\begin{tabular}{|c|c|c|c|c|c|c|c|c|}
\hline \multicolumn{9}{|c|}{ VARIABLES ANTRÓPICAS } \\
\hline & & & & & ALTERACI & ON TÉRMIC & & \\
\hline Individuo & $\begin{array}{c}\text { PASTO } \\
\text { DEBAJO }\end{array}$ & $\begin{array}{c}\text { ROCAS } \\
\text { SOBRE } \\
\text { HUESOS }\end{array}$ & $\begin{array}{c}\text { OCRE EN } \\
\text { SUP CORT } \\
\text { NISP/(\%) }\end{array}$ & $\begin{array}{l}\text { ALT TÉRM } \\
\text { TOTAL }\end{array}$ & $\begin{array}{l}\text { ALT TÉRM } \\
\text { PARCIAL }\end{array}$ & $\begin{array}{l}\text { ALT TÉRM } \\
\text { MÍNIMA }\end{array}$ & $\begin{array}{c}\text { ALT. } \\
\text { TÉRMICA } \\
\text { GRAL (\%) }\end{array}$ & $\begin{array}{c}\text { NISP } \\
\text { HUESOS }\end{array}$ \\
\hline CS.1 & $\mathrm{X}$ & $\mathrm{X}$ & $26(29,55)$ & 17 & 6 & 0 & 26,14 & 89 \\
\hline CS.2 & $\mathrm{X}$ & $\mathrm{X}$ & 0 & 1 & 2 & 0 & 75 & 4 \\
\hline CS.3 & $\mathrm{X}$ & $\mathrm{X}$ & 0 & 91 & 0 & 0 & 98,91 & 92 \\
\hline CS.4 & $\mathrm{X}$ & $\mathrm{X}$ & 0 & 126 & 4 & 0 & 100 & 130 \\
\hline CS. 5 & $\mathrm{X}$ & $\mathrm{X}$ & $29(59,18)$ & 12 & 21 & 0 & 67,35 & 49 \\
\hline CS.6 & $\mathrm{X}$ & $\mathrm{x}$ & $16(21,33)$ & 18 & 1 & 1 & 26,67 & 75 \\
\hline CS.8 & -- & -- & $1(100)$ & 0 & 0 & 0 & 0 & 1 \\
\hline CS.9• & -- & -- & 0 & 0 & 0 & 0 & 0 & 1 \\
\hline CS.10 & -- & -- & $1(100)$ & 0 & 0 & 0 & 0 & 1 \\
\hline TOTAL & $6 / 9$ & $6 / 9$ & 73 & 265 & 34 & 1 & 67,87 & 442 \\
\hline
\end{tabular}

-Restos humanos adicionales; X : presente; -- : ausente; Alt Térm: alteración térmica; NISP: número de especíenes identificados. 
En principio debe aclararse que la acción del fuego es de origen antrópico y previa a la cobertura del entierro con rocas y sedimento (información en Bird 1988: 211). El aspecto macroscópico de los huesos quemados es compatible con aquel observado en los huesos que tuvieron contacto con el fuego en estado fresco o con carne (Binford 1963; Buikstra y Swegle 1989; Shipman et al. 1984; Walker y Miller 2005).

De acuerdo con la bibliografía especializada, las cremaciones se han registrado con amplia extensión geográfica y cronológica y con una gran variabilidad de formas, aunque existen muchas similitudes en el rito de cremación a través del tiempo con pocas variaciones en el procedimiento y en las asociaciones culturales (Davies y Mates 2005). El término cremación se ha utilizado muchas veces para aludir tanto al acto de la quema de cadáveres humanos como a los resultados obtenidos, independientemente de cuales fueran (quemado, carbonización o calcinación de restos orgánicos). Aquí se considera que el simple hallazgo de restos óseos humanos quemados no implica necesariamente la práctica de una cremación de carácter ritual.

Se entiende como cremación una modalidad de entierro ritual que implica el quemado del/os cadáver/ es al aire libre en piras o en cavidades con material orgánico como combustible. El objetivo no religioso de la cremación es la reducción o degradación de los restos. Las principales manifestaciones arqueológicas son los deshechos de las estructuras del entierro (e.g. escombros de la pira, cavidad en el suelo, madera y vegetales) y las consecuencias observables sobre los tejidos duros del cuerpo, tales como la aparición de restos altamente fragmentados en estados de carbonización y/o calcinación (o de elementos enteros carbonizados y calcinados cuando la cremación no es completa u homogénea). La inhumación puede darse en el mismo sitio de la quema (ya sean entierros primarios o secundarios) o implicar un traslado de los restos en urnas (reducción de los huesos asociado con su transporte) (Davies y Mates 2005; Reverte 1984-85). En algunos casos los cuerpos podían ser quemados con objetos personales o del grupo y resulta frecuente la presencia de fauna asociada $u$ ofrendas de alimento en los sitios de entierro de cremación. La mayoría de estas cremaciones son múltiples y muchos sitios de pira (o con otro tipo de estructura) pudieron ser reutilizados en el tiempo (Davies y Mates 2005).
En los sitios con cremación, la mayoría de los huesos presentan una oxidación completa con una coloración blanca-azulada y variaciones en los niveles de oxidación (Davies y Mates 2005; Schmidt y Symes 2008). También pueden quedar fragmentos óseos sólo carbonizados por la mayor protección de los tejidos blandos en alguna partes del cuerpo o por la acción desigual del fuego, igualmente, para una cremación efectiva hay elementos que siempre confluyen: el fuego intencional, una temperatura mayor de $700 / 800^{\circ}$ grados y algún grado de reducción de los cuerpos (Buikstra y Swelge 1989; Davies y Mates 2005; Schmidt y Symes 2008).

La protección que otorga el espesor de la masa muscular de los huesos y la posición de los huesos en relación con el/los puntos de oxidación de consumición de las llamas (Binford 1969) es otro de los factores que deben tenerse en cuenta. En el caso de Cerro Sota, el combustible utilizado en la quema fue el pasto depositado por debajo, entre y encima de los cuerpos. Se considera que éste pudo haber tenido una distribución heterogéna debido a que la acción de la llamas afectó más algunos elementos y dejó libres del contacto con el fuego otros que pertenecían al mismo individuo (e.g. calota casi completamente quemada y el radio izquierdo sin alteración térmica de C.S.3). Esta diferencia se debió profundizar por la protección diferencial de la masa muscular de los diferentes elementos afectados. Igualmente es imposible hacer una evaluación de los focos de contacto y los sectores más afectados asociados con la mayor o menor protección muscular debido a la incompletitud del conjunto de esqueletos.

En Cerro Sota, la información contextual manifiesta el hallazgo de los esqueletos en su mayoría completos con los elementos en posición anatómica y articulados (Bird 1988: Fig.90). La ausencia, principalmente del esqueleto poscraneal, no se debería a la reducción ósea por el fuego ya que, como se señaló, los esqueletos se encontraban completos al momento de la excavación. Por esto, la prevalencia de calvarias y mandíbulas recolectadas y trasladadas pudo responder a una decisión de priorizar dichos elementos ante el mal estado de conservación que presentaban los huesos.

De acuerdo con lo planteado y con la falta de evidencia que sustente la cremación, se considera una mejor definición la combustion parcial del entierro para Cerro Sota teniendo en cuenta una 
alteracion térmica heterogénea y a veces superficial de los huesos presentes, la ausencia de evidencia de reducción de los restos y de huesos calcinados o completamente carbonizados. Esto tiene que ver con el material usado como combustible, la intensidad del fuego (temperaturas probablenente $<$ a $600^{\circ}$ ) y el tiempo que tuvieron contacto con el fuego, el cual debió ser moderado a bajo ya que su acción no fue suficiente para producir modificaciones severas y extensas generando restos óseos con grados de calcinación o carbonización (Buikstra y Swelge 1989; Schmidt y Symes 2008; Ubelaker 2009; Walker y Miller 2005). En suma, no hay evidencia de reducción o transformación por fuego de los restos humanos y el estado, coloración, severidad y extensión de los daños observados no se consideran sean las consecuencias arqueológicas de una cremación tal como fuera definida.

Por otro lado, debe aclarase que no existe evidencia osteológica que informe sobre las posible causas de muerte de este grupo de individuos. En un intento de explicar una inhumación simultánea de siete individuos, J. Bird en su libro esgrime las hipótesis de una muerte por violencia interpersonal o una accidental. Esta última posibilidad le resulta atractiva debido a que, en los niveles de ocupación inicial de la cercana cueva Fell (ca. $1 \mathrm{Km})$, halla el esqueleto de un caballo extinto articulado debajo de una serie de rocas procedente del techo de la cueva, por lo que relaciona un evento de derrumbe ocurido en Cueva Fell con la muerte de los individuos en cueva Cerro Sota (Bird 1988: 212). Así, asume que el grupo inhumado debió morir por las consecuencias de este evento catastrófico de derrumbe en Fell (una cueva con mejores condiciones de habitabilidad) y que los individuos fueron inhumados en Cerro Sota. En principio, en los materiales estudiados no se observaron las fracturas perimortem por compresión y cizallamiento esperables en un deceso traumático "por aplastamiento" tampoco otro tipo de lesiones que puedieran ser asociadas con violencia interpersonal. Por otro lado, este derrumbe verificado por J. Bird en Fell se ubica cronológicamente a fines del Pleistoceno (Bird 1988: 212), por lo que la correlación de estos hechos (derrumbe en Fell/ fauna pleistocénica y entierro en Cerro Sota) no es consistente debido a que posteriores fechados directos sobre los individuos de Cerro Sota los ubicaron a comienzos del Holoceno tardío.
Si bien no se cuenta con evidencia que permita plantear una hipótesis alternativa, se debe comentar que la estructura etarea de los individuos que integran la muestra está compuesta en su totalidad por adultos mayores y niños, dos grupos de edades que se consideran vulnerables ante condiciones climáticas adversas temporarias (e.g. inviernos extremos), la escaséz de recursos o ante afecciones epidemiológicas. Un caso muy similar se observa en Orejas de Burro 1 localizado a 38 Km de Cerro Sota y con una cronología comparable (L'Heureux y Barberena 2008), donde el entierro simultáneo de cinco individuos no registra evidencias osteológicas que puedan asociarse con la causa de muerte del grupo, el cual se compone de un alto porcentaje de individuos susceptibles de sufrir consecuencias mortales frente a distintos tipos de acontecimientos externos (dos neonatos, un infatil y un adulto mayor). Lamentablemente, la resolución de las reconstrucciones paleoclimátcas no permiten por el momento hacer inferencias ajustadas a cambios climáticos acontecidos en la escala del año o lustro y muchas enfermedades de descenlace rápido no necesariamente dejan rastros óseos.

Diferentes tipos de evidencia, zooarqueológica (Borrero 1984; Barberena et al. 2007; Campan et al. 2007; Caviglia y Figuerero Torres. 1976; L'Heureux 2008), bioarqueológica (Bird 1983, 1988; L'Heureux y Barberena 2008; Prieto 199394), lítica (Campan et al. 2007; Charlin 2009; Gómez Otero 1987; San Román et al. 2000) y geoarqueológica y cronológica (Barberena 2008) demuestran que la ocupación efectiva de los diferentes espacios del Campo Volcánico Pali Aike (CVPA) se inicia a comienzos del Holoceno tardío y se intensifica durante los últimos 2.000/2.500 años AP. Evidencia indirecta sustenta el incremento demográfico en el área desde el 4.000 AP. (Barberena 2008; Charlin 2009; L'Heureux 2009). Sin duda, el panorama que involucra la muerte de trece individos a comienzos del Holoceno tardío en Pali Aike meridional (cinco en OB1 y siete en Cerro Sota) se relaciona con una mayor mortalidad ante una densidad poblacional mayor que comenzaba a utilizar y explotar esta área hacia el 3.500 AP, aunque las causas de los decesos simultáneos aún deben seguir siendo estudiadas. 


\section{AGRADECIMIENTOS}

A Ian Tattersall y Gisselle García por permitirnos estudiar las muestras de los entierros excavados por Junius Bird depositadas en la Division of Anthropology, American Museum of Natural History (AMNH). A University of Iowa Press (copyright holder) por otorgar el permiso necesario para la reproducción de una de las imágenes del libro de J. Bird. A Ramiro Barberena por cedernos imágenes de la cueva. Este trabajo se realizó en el marco de la Pasantía Posdoctoral en el exterior del CONICET (Resolución D № 3351).

\section{BIBLIOGRAFÍA}

BABY, R. S. 1954. Hope well cremation practices. Papers in Archaeology 1. The Ohio Historical Society.

BARBERENA, R. 2002. Los límites del mar. Isótopos estables en Patagonia meridional. Sociedad Argentina de Antropología, Buenos Aires.

BARBERENA, R. 2008. Arqueología y biogeografía humana en Patagonia meridional. Sociedad Argentina de Antropología, Buenos Aires.

BARBERENA, R.; F. M. MARTIN y L. A. BORRERO. 2007. Estudio biogeográfico de conjuntos faunísticos: sitio Cóndor 1 (Pali Aike). En Arqueología de Fuego-Patagonia. Levantando piedras, desenterrando huesos... y develando arcanos. Pp. 139-150. Ediciones CEQUA, Punta Arenas.

BINFORD, L. R. 1963 The analysis of cremation from three Michigan sites. The Winsconsin Archaeologist 44:98-110.

BIRD, J. 1983. Enterratorios paleoindios con cremación en las cuevas de Palli-Aike y Cerro Sota en Chile meridional. Anales del Instituto de la Patagonia 14: 55-63.

1988. Travels and archaeology in South Chile. Editado por J. Hyslop. University of Iowa Press, Iowa.

BORRERO L. A. 1984. Informe preliminar sobre el material faunístico del sitio El Volcán 4. PREP-Informes de Investigación 1: 41-51. CONICET. Buenos Aires.

BUIKSTRA, J. E. y M. SWEGLE. 1989. Bone Modification Due to Burning: Experimental Evidence. En Bone modification, editado por R. Bonnischen y M. H. Sorg. Peopling of the Americas Publications, Center for the Study of the First Americans, Institute for Quaternary Studies, University of Maine, pp. 247-258.

BUIKSTRA, J. y D. UBELAKER (EDITORES). 1994. Standards for data collection from human skeletal remains. Arkansas Archaeological Survey Research Series 44, New York.
CAMPAN, P.; F. CARBALLO MARINA y L. M. MANZI. 2007. Arqueología de estancia La Carlota (Campo Volcánico Pali Aike, Argentina). En Arqueología de Fuego-Patagonia. Levantando piedras, desenterrando huesos... y develando arcanos. Pp. 687-699. Ediciones CEQUA, Punta Arenas.

CAVIGLIA, S. E. y M. J. FIGUERERO TORRES. 1976. Material faunístico de la cueva "Las Buitreras" (Dpto. Güer Aike, Provincia de Santa Cruz). Relaciones de la Sociedad Argentina de Antropología X:315-319, Buenos Aires.

CLARKE, N. G. y R. S. HIRSCH. 1991. Tooth dislocation: The relationship with tooth wear and dental abscesses. American Journal of Physical Anthropology 85:293-298.

DAVIES, D. J. y C. H. MATES (EDITORES). 2005. Encyclopedia of cremation. Ashgate Publishing Co. London.

D'ORAZIO, M.; S. AGOSTINI; F. MAZZARINI; F. INNOCENTI; P. MANETTI; M. J. HALLER y A. LAHSEN. 2000. The Pali Aike Volcanic Field, Patagonia: slab-window magmatism near the tip of South America. Tectonophysics 321:407-427.

GÓMEZ OTERO, J. 1987. Posición estratigráfica particular de puntas de los períodos IV y V de Bird en el alero PotrokAike (Santa Cruz). Primeras Jornadas de Arqueología de la Patagonia, pp. 125-130. Trelew.

HOLCK, P. 1996. Cremated Bones. Anatomical Institute, University of Oslo, Oslo.

HUSS-ASHMORE, R.; A. GOODMAN y G. ARMELAGOS. 1982. Nutritional inference from paleopathology. Advances in Archaeological Method and Theory. 5:395-474.

L'HEUREUX, G. L. 2008. La arqueofauna del Campo Volcánico Pali Aike. El sitio Orejas de Burro 1, Santa Cruz, Argentina. Magallania 36(1):65-76.

-2009. Aspectos adaptativos y microevolutivos de Lama guanicoe en la región volcánica de Pali Aike. Un estudio morfométrico de muestras arqueológicas y modernas. En Arqueología de Patagonia: una mirada desde el último confín, editado por M. Salemme, F. Santiago, M. Alvarez, E. Piana, M. Vázquez y M.E. Mansur, Pp. 773-787. Editorial Utopías, Ushuaia.

L'HEUREUX, G. L. y R. BARBERENA. 2008. Evidencias bioarqueológicas en Patagonia meridional: el sitio Orejas de Burro 1 (Pali Aike, Pcia. de Santa Cruz). Intersecciones en Antropología 9: 65-78.

MEINDL, R. S. y C. O. LOVEJOY. 1985. Ectocranial suture closure: a revised method for the determination of skeletal age at death based on the lateral anterior sutures. American Journal of Physical Anthropology 68: 57-66. 
NAMI, H. G. 1999. Arqueología en la localidad arqueológica de Pali Aike, cuenca del río Chico (Provincia de Santa Cruz, Argentina). Praehistoria 3: 189-218.

NEVES, W. A.; M. BLUM y L. KOZAMEH. 1999a. Were the Fuegians Relicts of a Paleoindian Nonspecialized Morphology in the Americas? Current Research in the Pleistocene 16: 90-92.

NEVES, W. A.; J. F. POWELL y E. G. OZOLINS. 1999 b. Extra-Continental Morphological Affinities of Palli Aike, Southern Chile. Interciencia 24 (4): 258-263.

PRIETO, A. 1993-94. Algunos datos en torno a los enterratorios de la región de Magallanes. Anales del Instituto de la Patagonia (Serie Ciencias Humanas) 22: 91-100.

REVERTE, J. M. 1984-85. Cremaciones prehistóricas en España. Anales de la Escuela de Medicina Legal de la Universidad Complutense de Madrid 1: 129-151.

SAN ROMAN, M.; F. MORELLO y A. PRIETO. 2000. Cueva de los Chingues (Parque Nacional Pali Aike), Magallanes, Chile. Historia natural y cultural I. Anales del Instituto de la Patagonia (Serie Ciencias Humanas) 28: 125-146.

SCHMIDT, C. W. y S. A. SYMES (EDITORES). 2008. The Analysis of Burned Human Remains. Elsevier Academic Press.

SCHUTKOWSKI, H. 1993. Sex determination on infant and juvenile skeletons: I. Morphognostic features. American Journal of Physical Anthropology 90: 199-205.

SCOTT, E. C. 1979. Dental wear scoring technique. American Journal of Physical Anthropology 51:213-218.
SHIPMAN, P., FOSTER, G., y M. SCHOENINGER. 1984. Burnt Bones and Teeth: An Experimental Study of Color, Morphology, Crystal Structure and Shrinkage. Journal of Archaeological Science 11.

SMITH, B. H. 1984. Patterns of molar wear in hunter-gatherers and agriculturalists. American Journal of Physical Anthropology 63:39-56.

SOTO-HEIM, P. 1994. Paleo Indian human remains of Patagonia-Chile. Current Research in the Pleistocene 11: 55-57.

STEELE, G. y C. BRAMBLETT. 1988. The Anatomy and Biology of the Human Skeleton. Texas A\&M University Press. College Station. Texas.

TURNER II, C. G. y J. B. BIRD. 1981. Dentition of Chilean Paleo-Indians and Peopling of the Americas. Science 212: 1053-1054.

UBELAKER, D. 2009. The fornsic evaluation of burned skeletal remains: a synthesis. Forensic Science International 183: $1-5$.

-1989. Human Skeletal Remains. Segunda edición. Taraxacum Press, Washington D. C.

WALDRON, T. 2009. Paleopathology. CambridgeManuals in Archaeology, Cambridge University Press. Cambridge.

WALKER P. L. y K. P. MILLER. 2005. Time, temperature, and oxygen availability: an experimental study of the effects of environmental conditions on the color and organic content of cremated bone. Journal of Physical Anthropology 40:216-217. 
